\title{
Collaborative mentoring to prepare doctoral students for college teaching
}

\author{
Lindsey B. Hogue, Kenneth Bleak, Tammy Abernathy \\ University of Nevada, Reno, United States.
}

\begin{abstract}
This project used psychosocial mentoring (Curtin et al., 2016) to create a collaborative mentoring experience to prepare doctoral students to become the instructors of record. In the collaborative mentoring experience, we paired doctoral students with a faculty member teaching a class that the doctoral student aspired to teach. The doctoral student observed the faculty member teaching, engaged in discussions with the faculty member, and reflected on the process. The following semester, the doctoral student became the instructor of record for the course. Following this experience, two doctoral students and one faculty member completed a retrospective self-study through journaling and discussions. After analyzing the results through discussions, we identified three themes: (1) understanding the course and our learners, (2) underlying goals and processes involved in college teaching, and (3) stretching the scope of practice for instructors of record. This paper describes the theme of stretching the scope of practice for instructors of record. Implications for teaching and learning in higher education are discussed.
\end{abstract}

Keywords: Psychosocial mentoring; doctoral students; higher education; college teaching; instructor of record. 


\section{Introduction}

In this project, our goal was to prepare special education doctoral students in a university program for higher education faculty positions. Although each doctoral student in our program had K-12 teaching experience, we found that students were not prepared for teaching in the college classroom. Guided by the concept of psychosocial mentoring (Curtin et al., 2016), our program developed a process we called collaborative mentoring, where a doctoral student was paired with a faculty member teaching a class that the doctoral student aspired to teach. Each doctoral student participated with and observed the faculty member teaching the course for one semester. The doctoral student and paired faculty member engaged in frequent discussions and the doctoral student reflected on the process. The following semester, the doctoral student assumed responsibility for the course as the instructor of record. The purpose of this project was to examine the learning experiences of two doctoral students and one faculty member who engaged in this collaborative mentoring experience. This study examines how psychosocial mentoring through our collaborative mentoring process prepared doctoral students to become the instructor of record for the first time and provided a faculty member with an opportunity to stretch the scope of her instructional practice.

Curtin et al. (2016) discussed three conceptualizations of mentoring in graduate education: (1) psychosocial mentoring, a process by which the faculty member allows their doctoral student to see firsthand the activities and experiences of the faculty member; (2) instrumental mentoring, where a faculty member offers explicit instruction through mentoring; and (3) sponsorship mentoring, where a faculty member advocates or allows access to their network for their doctoral student. Psychosocial mentoring develops a learning community through the mentor's sharing of their practice, thoughts, plans, and reflections with the mentee (Curtin et al., 1996). Lin et al. (2018) elaborated on this notion of learning communities and suggested that the creation of mentor and mentee learning communities would lead to enhanced confidence and the development of self-efficacy, which is a person's belief in their ability to understand and complete necessary tasks (Lent et al., 1994). According to Curtin et al. (2016), psychosocial mentoring is much less common in graduate settings than instrumental and sponsorship mentoring. This is problematic because instrumental and sponsorship mentoring can build knowledge and refine practice, but these methods have little effect on self-efficacy and offer little help in adapting practice to a new setting. That is, instrumental and sponsorship mentoring can teach one how to complete a specific task, but not how to generalize to a new task.

Psychosocial mentoring is strongly influenced by aspects of Bandura's (2001) social cognitive theory and Lent's (1994) application of social cognitive theory into social cognitive career theory. In social cognitive theory, Bandura (2001) suggested that a person's situational agency, along with a person's ability to reflect on their practice, created a vehicle for the 
person to enhance their situational self-efficacy. Lent et al. (1994) adapted social cognitive theory into social cognitive career theory, which focused on various types of mentoring and how mentoring can develop self-efficacy in a mentee's career. In our project, we anticipated that psychosocial mentoring would lead to enhanced doctoral student self-efficacy in their instructional role as they moved into positions in higher education (Curtin et al., 2016; National Academies of Sciences, Engineering, and Medicine, 2019). Because the doctoral student had access to the mentor's every plan, goal, practice, and outcome, the doctoral students could extend their experiences beyond the shared experience (Fletcher, 2018; Lent et al., 1994; National Academies of Sciences, Engineering, and Medicine, 2019).

This project connected aspects of psychosocial mentoring into a collaborative mentoring project designed to prepare doctoral students for college teaching. For this study, collaborative mentoring allowed the doctoral students and faculty member to learn through their shared experience.

\section{Method}

In this project, two doctoral students, Kenneth and Lindsey, and one faculty member, Tammy, retroactively examined the quality and impact of their separate collaborative mentoring experiences. Tammy, the faculty member participating in this project, is a professor with 30 years of experience in higher education. She has received several college teaching awards. Kenneth and Lindsey are both beyond the midpoint of their doctoral degrees and are transitioning to independent research and teaching. Both doctoral students specialize in high-incidence disabilities and teacher preparation. For Kenneth's collaborative mentoring experience with Tammy, he chose EDSP 444/644 Special Education Curricula: Secondary Students, a combined undergraduate and master's class required for special education teacher licensure in Nevada. Lindsey chose EDSP 411/611 Teaching Students with Disabilities in the General Education Classroom as her collaborative mentoring experience with Tammy. This course is an undergraduate and master's class geared toward students seeking secondary teaching licenses. Both courses are conducted in a three-hour, in-person, once per week format.

\subsection{Procedure}

This project used a retrospective self-study process as a methodology to study professional practice, settings, people, and assumptions (Loughran, 2004). Self-study is a recursive process that prioritizes questioning results, asking deeper questions, and responding to questions (Loughran, 2004). Figure 1 depicts a procedural diagram of our retrospective selfstudy. 

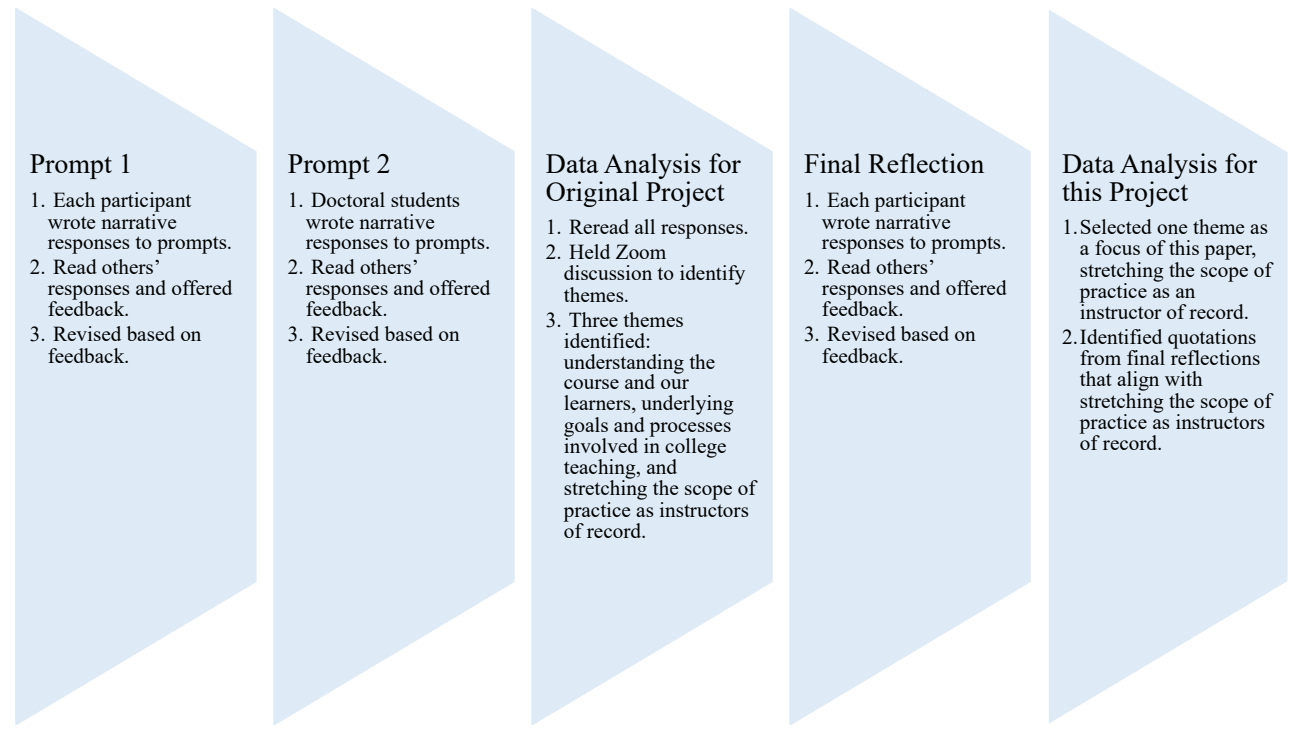

Figure 1. Procedural Diagram for the Project.

The data were collected through three prompts; each prompt had three rounds. For the first prompt, Tammy asked the doctoral students, Kenneth and Lindsey, to describe their expectations prior to the course and their overall experiences in the collaborative mentoring process. In turn, Kenneth and Lindsey asked Tammy to describe how having a doctoral student in the class influenced her instruction. For the second prompt, Tammy asked the doctoral students to describe their perspectives of Tammy's instructional decisions, including the syllabus, assignments, and instructional style.

After completing three rounds on the first and second prompts, we analyzed the narrative responses through rereading each response and discussing themes over a conference call. In this discussion, we identified three themes: understanding the course and our learners, underlying goals and processes involved in college teaching, and stretching the scope of practice for instructors of record. In this paper, we focus on the third theme, stretching the scope of practice for instructors of record.

Following data analysis, each participant wrote a final narrative response, which we called a final reflection. Kenneth and Lindsey had transitioned into the role of college instructor and described in their responses how the collaborative mentoring experience impacted their experience as instructor of record. Tammy added a narrative response describing her reflections on the collaborative mentoring experience as a whole. Each final reflection added new ideas to the theme of stretching the scope of practice for instructors of record. Quotations related to this theme were selected to add to this paper, which focuses solely on stretching the scope of practice for instructors of record. 


\section{Results}

In our retrospective self-study, the data were organized into three themes: (1) understanding the course and our learners, (2) underlying goals and processes involved in college teaching, and (3) stretching the scope of practice for instructors of record. We are highlighting the theme of stretching the scope of practice for instructors of record for this paper because of the insights we gained about teaching and learning in higher education.

The collaborative mentoring process allowed Lindsey and Kenneth to stretch their practice by reducing their anxiety related to becoming the instructor of record for a college class. Kenneth's anxiety with being the instructor of record centered on how he would handle difficulties that might arise in class sessions. In his final reflection, Kenneth wrote that while observing Tammy, "I had witnessed how to respond to difficult questions and to overcome the challenges created by students as they struggle with difficult concepts and ideas." By learning how to overcome challenges in the classroom, Kenneth processed his anxiety and stretched himself an instructor who could address students' challenges and questions with confidence.

Lindsey also felt anxious before becoming the instructor of record. Lindsey explained that she benefited from frequent conversations with Tammy about college instruction, which helped her discard her idea of perfection in teaching. For example, Tammy told Lindsey to think about whether the ongoing writing assignment was necessary for students to achieve the course goals. This showed Lindsey that Tammy was willing to reflect on her instructional choices and make changes to her approach each time she taught the class. In her final reflection, Lindsey wrote that after each class as instructor of record, "I tried to reflect on the things that went well and the things I could do better after each class, because I wanted to be one of those professors who continually strived for growth." In conversations with Tammy during the collaborative mentoring experience, Lindsey observed Tammy reflecting on her instructional choices. Because of this, Lindsey realized that no class session was perfect, and what is perfect for one student is not perfect for another. Instead, Lindsey used the tools she gained from the collaborative mentoring experience with Tammy to reflect on her own teaching when she became the instructor of record. Time for reflection ultimately lessened her anxiety.

Through the collaborative mentoring experience, Kenneth and Lindsey gained the selfefficacy they needed to stretch into the role of instructor of record. Kenneth explained in his first journal response that because of the time he spent in Tammy's classroom, "I would never be walking into a class I need to teach without the memories of the content being taught. I have always relied heavily on my memory and it makes me more comfortable having had the experience." For Kenneth, the collaborative mentoring experience provided a level of comfort that he took with him into his own classes as the instructor of record, which increased 
his confidence in his college teaching abilities. Lindsey added in her final reflection that Tammy explained how she made curriculum and instructional decisions, which helped Lindsey increase her confidence in her own curriculum and instructional decision-making. "I was able to make these decisions because I felt confident in my own judgment. I do not think I would have felt this confidence if I had been dropped into the course cold." For example, as instructor of record, Lindsey chose to repeat Tammy's learning disabilities simulation because she observed high levels of engagement in the students; Lindsey chose not to repeat Tammy's lecture on RTI because she did not have as much knowledge on the subject and there was a strong online learning module available.

While the collaborative mentoring experience increased the doctoral students' levels of selfefficacy, it disrupted Tammy's everyday practice as an established, well-regarded instructor. In her first journal, she reflected, "I felt like a novice teacher who needed to give a rationale for every topic, every reading, every activity and every interaction." Tammy explained that it made her nervous to bring doctoral students in to "watch me teach, to evaluate my teaching, to consider how they might do things differently." This experience compelled Tammy to analyze her teaching practices. Tammy added in her final reflection, "This experience forced me to boldly and baldly face my challenges, critique my own thinking, and face the notion that as I age, I may be losing my connections with my students and perhaps even my everchanging content." While the collaborative mentoring experience was challenging for Tammy, she explained that she felt it was important for established instructors to "face disequilibrium" in their teaching so that they may stretch the scope of their teaching practice.

Each participant stretched the scope of their teaching practice through the collaborative mentoring experience. Kenneth and Lindsey increased their sense of self-efficacy and learned strategies they would use in their own college classrooms. Tammy stretched her teaching practice by examining her instructional choices through conversations with the doctoral students.

\section{Discussion}

University professors are responsible for the education and mentorship of all students regardless of their academic level. Undergraduates should receive high quality instruction to prepare them for their chosen profession. Undergraduates may have graduate students as instructors, but that should not expose them to lesser quality instruction. Professors are also mentors invested in the futures of their graduate students. Additionally, professors are stewards of their profession and are responsible for preparing future faculty who are ready to excel in higher education from the first date of hire. This project met these responsibilities. Our goal of creating a collaborative mentoring model to prepare doctoral students and not expose undergraduates to substandard instruction was met in this project. 
Prior efforts to mentor doctoral students in our program included static models of mentoring, such as instrumental or sponsorship models, where faculty met with students to check in or scheduled group meetings for discussion; these mentoring models were not effective in our program. Developing a psychosocial model of collaborative mentoring allowed our program to meet our goals of high-quality instruction for all. One feature of our collaborative mentoring model was the vulnerability of the participants. In this model, there was no room for faculty to hide as every instructional episode was observed, critiqued and discussed. These collaborative experiences impacted each participant. The doctoral students gained confidence and reduced their anxiety by watching Tammy deal with difficult situations and understanding why she made certain instructional choices. The doctoral students were able to take their ability to critique instruction and reflect upon the experience with Tammy to alter, improve, or celebrate their own success. The idea that the doctoral students and the mentor had shared experiences in the same environments to learn from made the psychosocial approach effective compared to more static, distal, and simple check-in type mentoring.

As Curtin et al. (2016) suggested, our collaborative mentoring model did not come without risk. In this project, the risk for doctoral students related to their anxiety around working with their mentors as equals in the collaborative process. The switch from student to colleague can be challenging, but it is important that students be given opportunities to share their point of view at the risk of disagreeing with mentors. While uncomfortable at first, doctoral students tactfully became thoughtful, expressive, and fully collaborative colleagues. This transition was a key part of their preparation for positions in higher education.

The faculty member, the mentor, should be willing to be vulnerable in front of doctoral students who hold the mentor in high esteem. The process was intrusive because the faculty mentor taught undergraduates and doctoral students at the same time with different objectives. This multitasking felt risky. It forced the person of status to be an equal member of a community with his or her students. This may not be comfortable for all professors.

Psychosocial mentoring, the shared experience of an authentic partnership in a collaborative classroom, made the difference for the doctoral students in our project because in this environment the students experienced every success and failure along with their mentor. Overall, the reward for this collaborative effort was the confidence doctoral students gained in teaching their courses. This experience was key to building and maintaining confidence for emerging academics as it allowed them to extend the experience into their future.

\section{References}

Bandura, A. (2001). Social cognitive theory: An agentic perspective. Annual Review of Psychology, 52, 1-26. doi: 10.1146/annurev.psych.52.1.1 
Curtin, N., Malley J., \& Stewart A. J. (2016). Mentoring the next generation of faculty: Supporting academic career aspirations among doctoral students. Research in Higher Education, 57(6), 714-738. doi: 10.1007/s11162-015-9403-x.

Fletcher, J.A., (2018). Peer observation of teaching: A practical tool in higher education. The Journal of Faculty Development, 32(1), 51-64.

Lent, R.W., Brown, S.D., \& Hackett, G. (1994). Toward a unifying social cognitive theory of career and academic interest, choice, and performance. Journal of Vocational Behavior, 45(1), 79-112. doi: 10.1006/jvbe.1994.1027

Lin, X., Cordie, L., \& Witte, M. (2018). Mentoring a learning community: A student research empowerment program for adult education graduate students. International Forum of Teaching and Studies, 14(1), 26-49.

Loughran, J. (2004). International handbook of self-study of teaching and teacher education practices. Boston, MA: Kluwer Academic.

National Academies of Sciences, Engineering, and Medicine. (2019). The science of effective mentorship in STEMM. Washington, DC: The National Academies Press. doi: $10.17226 / 25568$ 